\title{
Differentiation of communicating hydrocephalus and presenile dementia by continuous recording of cerebrospinal fluid pressure
}

\author{
A. H A R T M A N A N D E. A LBERTI \\ From the Neurological Clinic, University of Heidelberg, Heidelberg, Germany
}

SUMMARY Continuous monitoring of the cerebrospinal fluid pressure and observation of the pressure during intrathecal infusion of normal saline at two rates were performed in patients with communicating hydrocephalus and cerebral atrophy of other causes. Constant or temporarily increased cerebrospinal fluid pressure was observed only in communicating hydrocephalus. Reduction of intracranial pressure by a ventriculoatrial shunt was associated with clinical improvement. The intrathecal infusion test was capable of detecting reduced absorption of cerebrospinal fluid if more than one infusion rate was employed. Using both tests it is easier to determine which patients with communicating hydrocephalus should be treated with a shunt operation.

Ventriculoatrial shunts are employed in patients with communicating hydrocephalus to equalise the deficient absorption of the cerebrospinal fluid (CSF) in the presence of a constant CSF production (Hussey et al., 1970). Because of obstruction in the intracranial subarachnoid space, the accumulation of CSF causes an initial elevation of the intracranial pressure and dilatation of the ventricular system without cortical atrophy (hydrocephalus internus). Alteration of the intracranial pressure and decreased cerebral blood flow by compression of cerebral vessels (Greitz et al., 1969; Mathew et al., 1975) are accompanied by the clinical picture of dementia, apraxia or other disorders of gait, incontinence of urine, and additional symptoms (Adams et al., 1965). Diagnostic approaches such as pneumoencephalography and isotope CSF scintigraphy are sometimes misleading in the differentiation between patients with communicating hydrocephalus and presenile dementia, and thus cannot give a reliable indication for surgical therapy (Shenkin et al., 1973). For this reason other diagnostic procedures such as intrathecal infusion of normal saline with control of CSF pressure (Hussey et al., 1970), or continuous monitoring of intracranial pressure have been introduced (Symon, 1972).

This report presents our observations on con- tinuous recording of CSF pressure and its reaction to intrathecal infusion in patients with communicating hydrocephalus and cerebral atrophy. The method here described involves lumbar puncture only and can be done at the bedside (Hartmann and Alberti, 1977). Garretson and Brindle (1972) demonstrated that the intraventricular pressure equals the lumbar pressure. In a few patients with communicating hydrocephalus we have performed simultaneous recordings of intraventricular and lumbar cerebrospinal fluid pressure (Fig. 1), and we confirm the statement of Kaufman and Clark (1970) that only an obstruction between both points of measurement leads to a pressure gradient.

This study was designed to answer the following questions:

1. Is CSF pressure normal in all patients who are classified as having communicating hydrocephalus?

2 Can continuous monitoring of CSF pressure be used as a diagnostic tool in establishing the diagnosis, and can it be used for selection of patients for surgery?

3 Is the intrathecal infusion test capable of separating both groups?

\section{Method}

The patients were placed in the lateral recumbent 


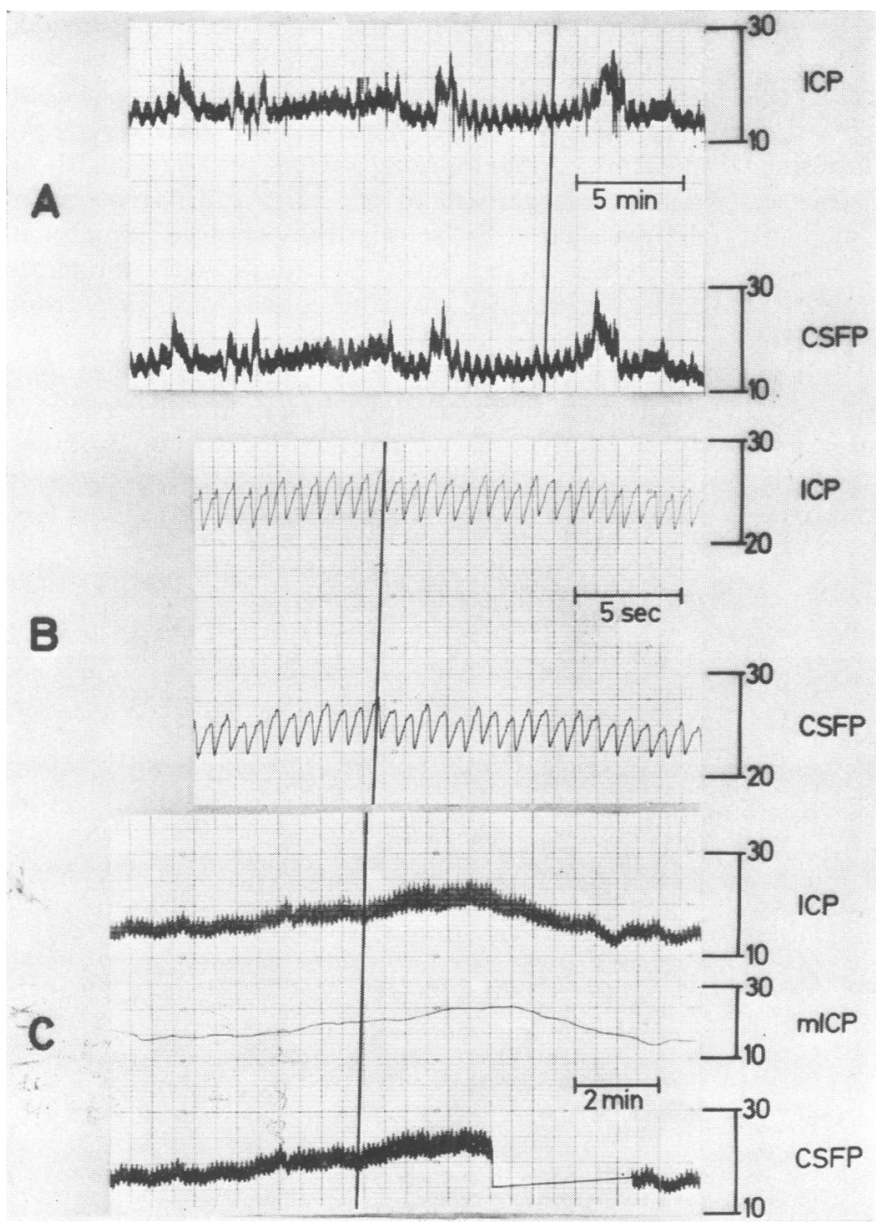

Fig. 1 Simultaneous recording of intraventricular (ICP) and lumbar subarachnoid (CSFP) cerebrospinal fluid pressure in case 14. Charts read from right to left. A: low chart speed. ICP almost equals CSFP. B: high speed. A minimal damping of CSFP can be noted. $C$ : low speed. $3 \mathrm{ml}$ normal saline were injected through the lumbar route within 3 min. CSFP is slightly higher than ICP otherwise the reactions of $I C P$ and CSFP are identical. mICP $=$ mean ICP. Black line $=$ time axis.

position. A lumbar puncture was performed with a needle which was slightly bent $\left(35^{\circ}\right)$ at its tip. After insertion of the needle into the subarachnoid space the stilette was removed, and a gas sterilised polyethylene catheter was introduced. The inner diameter of the catheter was $0.5 \mathrm{~mm}$, and the outer $1.0 \mathrm{~mm}$. The needle itself was removed and the outer end of the catheter connected to a threeway stopcock and thus to a transducer (Statham PDb 23). The chamber of the strain gauge and the polyethylene catheter were filled with sterile normal saline. In this way the CSF pressure was recorded on a Rikadenki 4channel polygraph. The transducer was placed on the same level as the third ventricle. The skin around the point of the puncture was carefully covered with sterile cotton and tape. The patient was placed in a horizontal position. The CSF pressure and the mean CSF pressure were moni- tored for 24 to 36 hours. The procedure was painless and no complications occurred.

At the end of the study one end of the threeway stopcock at the transducer was connected to a non-pulsing infusion pump. For the intrathecal infusion study sterile normal saline was used; the patients were lightly sedated with diazepam. The infusion rate was $0.92 \mathrm{ml} / \mathrm{min}$ for $60 \mathrm{~s}$, thereafter CSF pressure was recorded for $15 \mathrm{~s}$. These alternating infusion and recording procedures were repeated as long as the patient did not complain of headache or nausea. If the patient tolerated the infusion well, the study was stopped after 60 min or at a CSF pressure of $50 \mathrm{mmHg}$. In some patients an additional infusion rate of $1.84 \mathrm{ml} / \mathrm{min}$ was employed, again with a recording time of $15 \mathrm{~s}$ between two episodes of $60 \mathrm{~s}$ of infusion. Thus the absolute infusion rate was $0.74 \mathrm{ml} / \mathrm{min}$ for the lower rate and $1.47 \mathrm{ml} / \mathrm{min}$ for the higher rate. 


\section{Patients}

We report the study of 27 patients consecutively admitted to our clinic. Table 1 lists age, sex, diagnosis, a summary of the clinical symptoms, and an estimation of the duration of the disease. All patients underwent detailed general medical and neurological examinations. They were evaluated by radiographs of the skull, electroencephalography, brain scanning, cerebral angiography, pneumoencephalography, either ${ }^{111}$ Indium HSA or ${ }^{169}$ Ytterbium DTPA SCF scintigraphy, continuous recording of the CSF pressure, and intrathecal infusion test. According to the case history, clinical aspects, pneumoencephalography, and CSF scintigraphy, the individuals were divided into two groups, one containing the patients who presented with signs and symptoms of communicating hydrocephalus. All showed in the pneumoencephalogram dilated ventricles without visible enlargement of the sulci and narrowing of the gyri. The CSF scintigraphy showed a ventricular reflux of at least 24 hours with moderate delayed clearance over the convexities. This group will be called the ' $\mathrm{CH}$-group'.

The second group was composed of patients who were suspected of having an alteration of intellectual performance not due to communicating hydrocephalus. The pneumoencephalogram showed combined hydrocephalus internus and

Table 1 Summary of clinical data. Patients 1-14: communicating hydrocephalus group, patients 15-27: control group

\begin{tabular}{|c|c|c|c|c|c|}
\hline Patient & $\begin{array}{l}\text { Age } \\
(y r)\end{array}$ & $\operatorname{Sex}$ & Diagnosis & Clinical summary & $\begin{array}{l}\text { Duration } \\
\text { of disease } \\
\text { (months) }\end{array}$ \\
\hline 1 & 54 & $\mathbf{F}$ & $\begin{array}{l}\mathrm{CH}^{*} \text { after extirpation of } \\
\text { falx meningioma }\end{array}$ & $\begin{array}{l}\text { Progressive dementia, urinary incontinence, hemiparesis, } \\
\text { Jacksonian fits }\end{array}$ & 36 \\
\hline 2 & 40 & $\mathbf{M}$ & $\begin{array}{l}\mathrm{CH} \text { after head injury, } \\
\text { idiopathic epilepsy }\end{array}$ & Progressive dementia, urinary incontinence & 12 \\
\hline 3 & 36 & $\mathbf{M}$ & $\begin{array}{l}\mathrm{CH} \text { after excision of } \\
\text { ependymoma, radiation }\end{array}$ & $\begin{array}{l}\text { Alteration of intellectual capability, alteration of personality, } \\
\text { paresis of left leg }\end{array}$ & 6 \\
\hline 4 & 40 & $\mathbf{M}$ & $\begin{array}{l}\mathrm{CH} \text { after } \mathrm{SAH}, \dagger \text { aneurysm } \\
\text { of the ant. comm. artery }\end{array}$ & $\begin{array}{l}\text { Progressive dementia, urinary incontinence, hemiparesis, } \\
\text { hemianopia, aphasia, gait ataxia }\end{array}$ & 2 and 4 \\
\hline 5 & 19 & $\mathbf{F}$ & $\begin{array}{l}\mathrm{CH} \text { with tuberculous meningitis, } \\
\text { miliary tuberculosis }\end{array}$ & $\begin{array}{l}\text { Fluctuation of consciousness, progressive dementia, urinary } \\
\text { incontinence, abducens paresis, spasticity of the lower limbs }\end{array}$ & 4 \\
\hline 6 & 19 & $\mathbf{M}$ & CH after SAH & $\begin{array}{l}\text { Progressive dementia, urinary incontinence, abducens and } \\
\text { facial paresis }\end{array}$ & 3 \\
\hline 7 & 67 & $\mathbf{F}$ & $\begin{array}{l}\mathrm{CH} \text { after SAH, aneurysm of } \\
\text { the ant. comm. artery }\end{array}$ & $\begin{array}{l}\text { Dementia, altered personality, urinary incontinence, } \\
\text { hemiparesis, gait ataxia }\end{array}$ & 6 \\
\hline 8 & 50 & $\mathbf{F}$ & $\begin{array}{l}\mathrm{CH} \text { after } \mathrm{SAH} \text {, intracerebral } \\
\text { haematoma }\end{array}$ & $\begin{array}{l}\text { Progressive dementia, urinary incontinence, hemiparesis, } \\
\text { gait ataxia }\end{array}$ & 1 \\
\hline 9 & 49 & $\mathbf{M}$ & $\mathrm{CH}$ after SAH & Progressive dementia, urinary incontinence, hemiparesis & 3 \\
\hline 10 & 57 & $\mathbf{F}$ & $\begin{array}{l}\text { CH after SAH, aneurysm } \\
\text { of the basilar artery }\end{array}$ & $\begin{array}{l}\text { Fluctuation of consciousness, dementia, urinary incontinence, } \\
\text { gait ataxia }\end{array}$ & 7 \\
\hline 11 & 66 & $\mathbf{M}$ & $\begin{array}{l}\text { CH after head trauma } \\
\text { chronic subdural haematoma }\end{array}$ & Progressive dementia, urinary incontinence, gait ataxia & 5 \\
\hline 12 & 65 & $\mathbf{F}$ & $\begin{array}{l}\text { CH after SAH, meningitis, } \\
\text { aneurysm of the ant. comm. art. }\end{array}$ & $\begin{array}{l}\text { Progressive dementia, incontinence of bladder and bowel, } \\
\text { hemiparesis, paresis of the oculomotor nerve, cerebellar ataxia }\end{array}$ & 3 \\
\hline 13 & 65 & $\mathbf{F}$ & $\mathrm{CH}$ after brain radiation & $\begin{array}{l}\text { Progressive dementia, urinary incontinence, hemiparesis, } \\
\text { gait apraxia }\end{array}$ & 48 \\
\hline 14 & 62 & $\mathbf{M}$ & $\mathrm{CH}$ after repeated $\mathrm{SAH}$ & $\begin{array}{l}\text { Progressive dementia, urinary incontinence, spasticity of the } \\
\text { lower limbs, gait ataxia }\end{array}$ & 3 \\
\hline 15 & 41 & $\mathbf{F}$ & Condition after SAH & Alteration of intellectual capability and emotional behaviour & 1 \\
\hline 16 & 68 & $\mathbf{F}$ & $\begin{array}{l}\text { Cerebral arteriosclerosis, } \\
\text { Parkinsonism, symptomatic } \\
\text { epilepsy }\end{array}$ & Dementia, tremor, hypokinesia, rigidity, urinary incontinence & 72 \\
\hline 17 & 63 & $\mathbf{F}$ & Alzheimer's disease & Progressive dementia, urinary incontinence & 5 \\
\hline 18 & 66 & $\mathbf{F}$ & Porencephaly & $\begin{array}{l}\text { Fluctuation of consciousness, dementia, urinary incontinence, } \\
\text { gait apraxia }\end{array}$ & 60 \\
\hline 19 & 60 & $\mathbf{F}$ & Alzheimer's disease & Progressive dementia, akinesia, tremor & 6 \\
\hline 20 & 54 & $\mathbf{M}$ & $\begin{array}{l}\text { Alzheimer's disease, } \\
\text { symptomatic epilepsy }\end{array}$ & Progressive dementia, hemiparesis, gait ataxia, rigidity & 36 \\
\hline 21 & 62 & $\mathbf{F}$ & Alzheimer's disease & Dementia, hemiparesis, gait ataxia, aphasia & 24 \\
\hline 22 & 67 & $\mathbf{F}$ & Alzheimer's disease & Dementia, fluctuation of consciousness, aphasia, alexia, apraxia & 60 \\
\hline 23 & 57 & $\mathbf{M}$ & Pick's disease & Progressive dementia, hemiparesis, apraxia & 24 \\
\hline 24 & 64 & $\mathbf{M}$ & Alzheimer's disease & $\begin{array}{l}\text { Progressive dementia, urinary incontinence, apraxia, aphasia, } \\
\text { hypokinesia }\end{array}$ & 18 \\
\hline 25 & 63 & $\mathbf{F}$ & Alzheimer's disease & Progressive dementia, apraxia, aphasia & 60 \\
\hline 26 & 61 & $\mathbf{M}$ & Alzheimer's disease & $\begin{array}{l}\text { Progressive dementia, urinary incontinence, gait apraxia, } \\
\text { hemiparesis }\end{array}$ & 12 \\
\hline 27 & 60 & $\mathbf{M}$ & Alzheimer's disease & Dementia, urinary incontinence & 11 \\
\hline
\end{tabular}

* $\mathrm{CH}=$ communicating hydrocephalus; † $\mathrm{SAH}=$ subarachnoid haemorrhage. 
externus. The CSF scintigraphy revealed a ventricular reflux of less than 24 hours and no, or only slightly, delayed clearance. These patients were diagnosed as not having communicating hydrocephalus and will be listed in the so-called "control group'.

To evaluate the usefulness of continuous monitoring of the CSF pressure and the intrathecal infusion test, the results of these tests were not used for classification of the patients.

\section{Results}

Table 2 gives a summary of the data on the CSF pressure monitoring: the level and range of the CSF pressure without consideration of plateau waves, the occurrence of plateau waves, the type of reaction of the CSF pressure to intrathecal infusion, the maximum CSF pressure during the infusion, and the time taken to achieve the maximum CSF pressure. In the $\mathrm{CH}$-group eight out of 14 patients had a CSF pressure range which sometimes exceeded $15 \mathrm{mmHg}$. Patient 4 was monitored twice. Four weeks after his subarachnoid haemorrhage an increased pressure was observed. Two months later the CSF pressure was almost normal.

In cases $1,3,5,7$, and 4 during the first monitoring, CSF pressure was increased while awake; in cases 2,12 , and 14 only when asleep. Nine patients presented with plateau waves of pressure (Fig. 2). In three cases $(1,5$, and 12) pressure rises were observed, which resembled the A-waves described by Lundberg (1960). In case 14 these A-waves occurred only six days after the bleeding (Fig. 3). In patients $1,4,5,7,9,10,11$, and 14 pressure elevations of shorter duration with characteristics of Lundberg's B-waves were observed (Fig. 2). In five individuals of the $\mathrm{CH}$-group plateau waves did not appear. The maximum height of the plateau waves was $29 \mathrm{mmHg}$ above the baseline pressure, which is lower than the plateau waves which we found in patients suffering from intracerebral tumours. During the phase of plateau waves the CSF pressure amplitude was increased (Figs. 2 and 3).

No definite correlation between the height of the CSF pressure and the occurrence of plateau waves was found. Two patients with increased CSF pressure did not show plateau waves whereas several patients with low CSF pressure did.

Six patients were monitored again after shunt surgery. In all cases CSF pressure had decreased (Table 2, Figs. 3, 4, and 5). Clinical improvement was observed in most of the patients. The effect on mental condition, gait, and urine control was dramatic in case 1 , who was able to return to housework about six weeks after surgery. With the other patients improvement was not striking, but was confirmed by their families. Patient 14 improved only in his gait. Patient 4 also received a shunt, but was not monitored again. His gait and urine control improved slightly. No complications were seen after surgery.

Table 2 Summary of data on CSF pressure monitoring and intrathecal infusion test. Patients 1-14: communicating hydrocephalus group, patients 15-27: control group

\begin{tabular}{|c|c|c|c|c|c|c|c|c|c|c|c|c|c|c|c|}
\hline Patient & $l$ & 2 & & & 4 & 5 & 6 & 7 & 8 & 9 & 10 & 11 & 12 & 13 & 14 \\
\hline \multirow[t]{2}{*}{ CSFP* before operation $(\mathrm{mmHg})$} & 22 & 14 & & & 2014 & 22 & 8 & 19 & 7 & 10 & 8 & 9 & 15 & 10 & 10 \\
\hline & 32 & 17 & & & 2615 & 39 & 12 & 26 & 14 & 12 & 14 & 14 & 20 & 13 & 26 \\
\hline \multirow{2}{*}{ CSFP after operation $(\mathrm{mmHg})$} & 22 & & & & & 11 & & 9 & & 9 & & 4 & & & 6 \\
\hline & 23 & & & & & 22 & & 16 & & 10 & & 11 & & & 12 \\
\hline \multirow{6}{*}{$\begin{array}{l}\text { Plateau waves } \\
\text { Infusion test with slow infusion rate } \\
\text { Maximum CSFP with slow infusion rate } \\
\text { (mmHg) } \\
\text { Time to achieve maximum CSFP (min) } \\
\text { Maximum CSFP with fast infusion rate } \\
\text { (mmHg) } \\
\text { Time to achieve maximum CSFP (min) }\end{array}$} & $\therefore-$ & - & & & $\therefore 1+$ & :- & - & $\therefore$ & 一 & $\rightarrow$ & $\div$ & $\therefore$ & $\therefore$ & $\ldots$ & + \\
\hline & B & $\mathrm{D}$ & & & $A_{+}^{+}$ & B & $\mathrm{C}$ & $\mathbf{A}$ & $\mathrm{C}$ & A & D & $\mathrm{C}$ & B & D & A \\
\hline & 42 & 37 & & & 40 & 52 & 35 & 46 & 38 & 28 & 30 & 34 & 46 & 36 & 46 \\
\hline & $20+$ & 21 & & & $11+$ & $28+$ & 60 & $17 \dagger$ & 60 & $16 \dagger$ & 22 & 60 & $39+$ & 32 & 14 \\
\hline & 44 & & & & & & 52 & & 46 & & & & & & \\
\hline & $9+$ & & & & & & $14+$ & & $13+$ & & $11+$ & $\begin{array}{l}37 \\
60\end{array}$ & & & \\
\hline \multicolumn{2}{|l|}{ Patient } & & 15 & 16 & 17 & 18 & 19 & 20 & 21 & 22 & 23 & 24 & 25 & 26 & 27 \\
\hline \multirow{2}{*}{\multicolumn{2}{|c|}{ CSFP $(\mathrm{mmHg})$}} & & 11 & 10 & 9 & 6 & 4 & 8 & 9 & 8 & 11 & 8 & 6 & 9 & 4 \\
\hline & & & 14 & 12 & 12 & 8 & 6 & 12 & 11 & 12 & 14 & 9 & 9 & 11 & 5 \\
\hline \multicolumn{2}{|l|}{ Plateau waves } & & 一 & - & - & - & - & - & - & - & - & - & - & - & - \\
\hline \multicolumn{2}{|l|}{ Infusion test with slow infusion rate } & & $\mathrm{C}$ & $\mathrm{C}$ & D & $\mathrm{C}$ & D & D & D & $\mathbf{D}$ & $\mathrm{C}$ & $\mathrm{C}$ & $\mathbf{C}$ & $\mathbf{D}$ & C \\
\hline Maximum CSFP with slow infusion rate ( & Hg) & & 26 & 24 & 34 & 24 & 37 & 26 & 27 & 34 & 31 & 30 & 37 & 33 & 16 \\
\hline \multicolumn{2}{|l|}{ Time to achieve maximum CSFP (min) } & & 60 & 60 & 23 & 60 & 22 & 13 & 16 & 40 & 60 & 60 & 60 & 41 & 60 \\
\hline \multicolumn{2}{|c|}{ Maximum CSFP with fast infusion rate $(\mathrm{mm} \mathrm{Hg})$} & & & 36 & & 27 & 37 & & 29 & 44 & & 47 & 42 & & 24 \\
\hline \multicolumn{2}{|l|}{ Time to achieve maximum CSFP (min) } & & & 60 & & $22 \dagger$ & $34 \dagger$ & & $46 \dagger$ & $31 \dagger$ & & $34 \dagger$ & $43 \dagger$ & & 60 \\
\hline
\end{tabular}

* CSFP $=$ cerebrospinal fluid pressure. The upper value indicates the lowest and the lower value the highest CSFP during 24 hours of recording;

+ infusion stopped because of headache and nausea; $\ddagger$ test during second monitoring. 


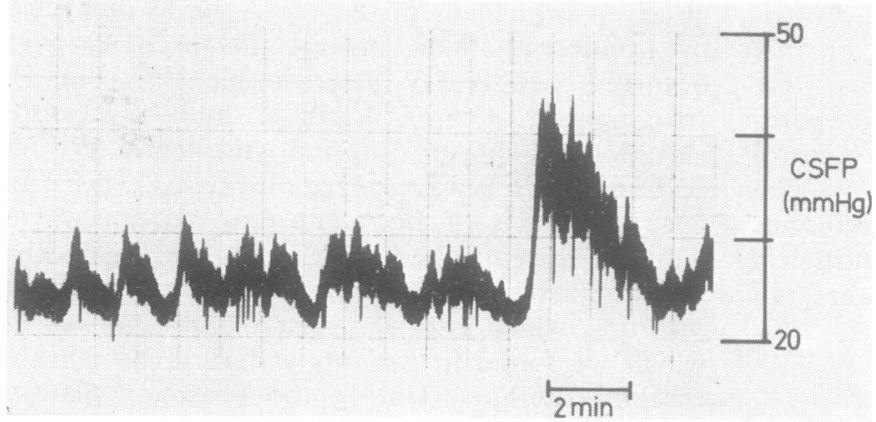

(a)

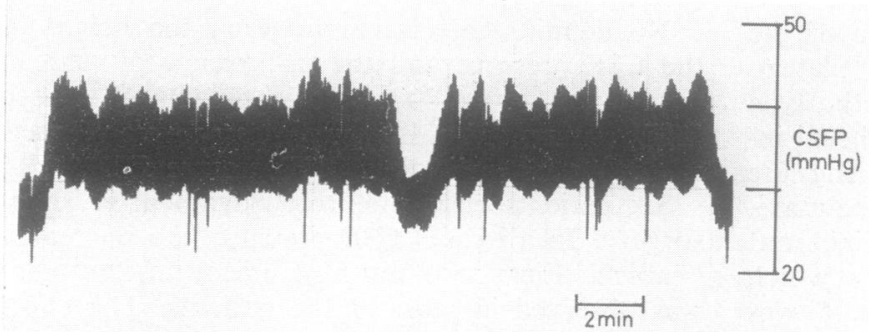

(b)

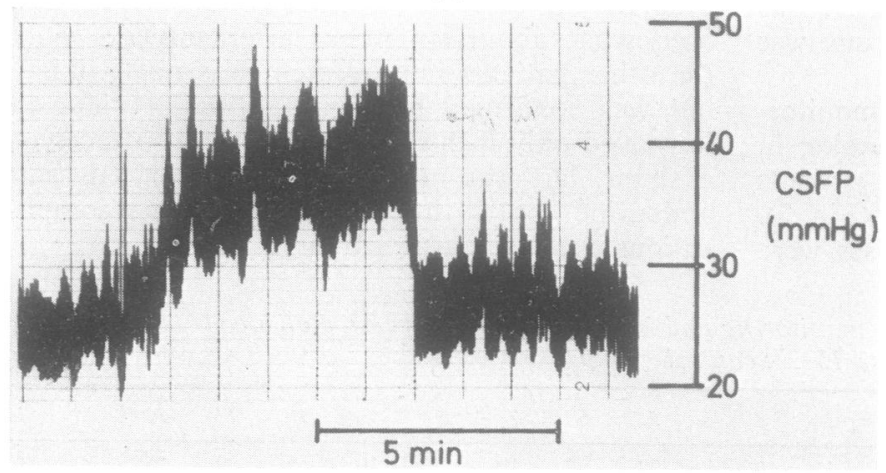

(c)
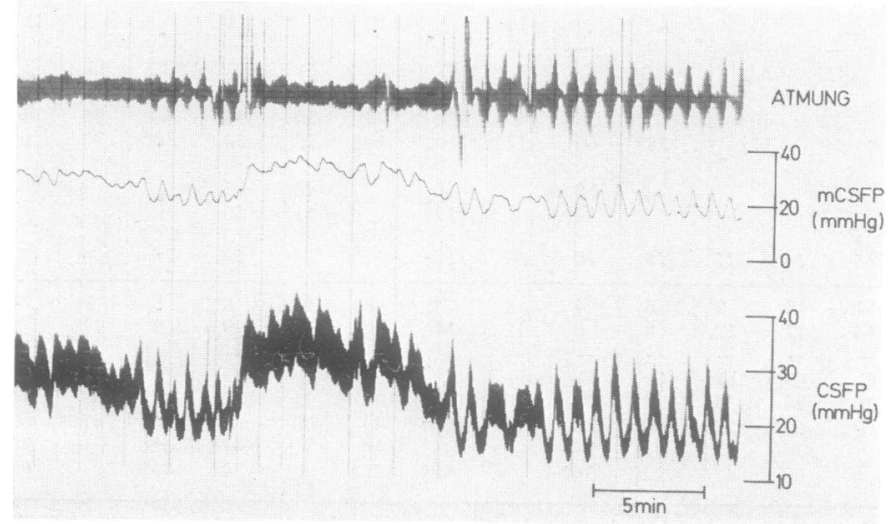

(d)
Fig. 2 Plateau waves. Charts read from right to left: $(a)$ and $(b)$ show breathingdependent waves, (c) a respirationindependent wave. (d) indicates the alteration of CSFP in dependency of respiration pattern. Atmung $=$ respiration. 


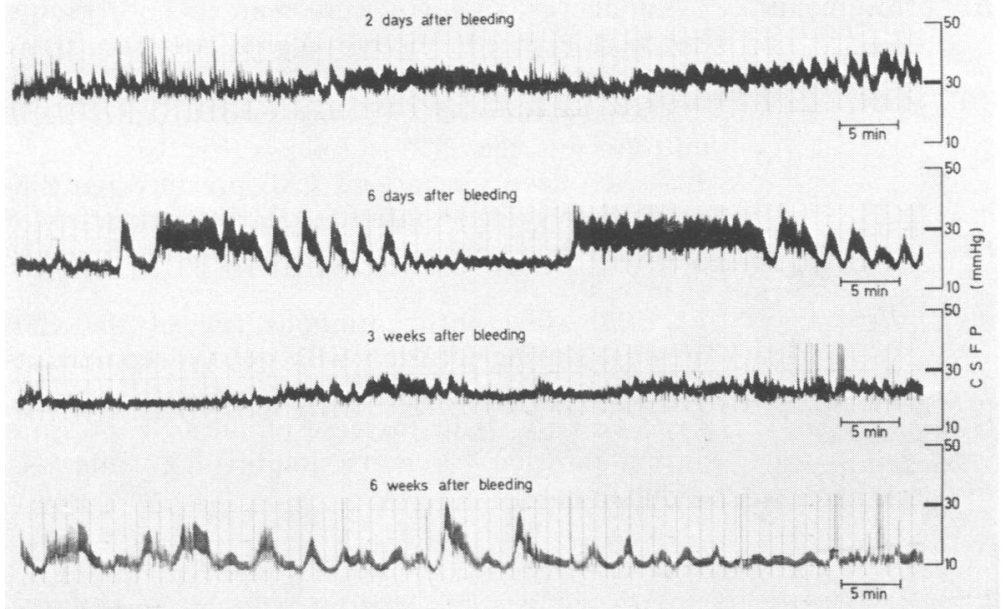

Fig. 3 Repeated CSFP monitoring. Curves read from right to left. (a) Patient 14. CSFP was recorded four times before surgery and once after shunting. Rebleeding occurred seven days before the third monitoring (' 3 weeks'). Over the time CSFP decreased, but peaks still appeared together with plateau waves. After surgery CSFP was reduced; (b) patients with increased CSFP four days after subarachnoid haemorrhage. CSFP was reduced 18 days after bleeding.

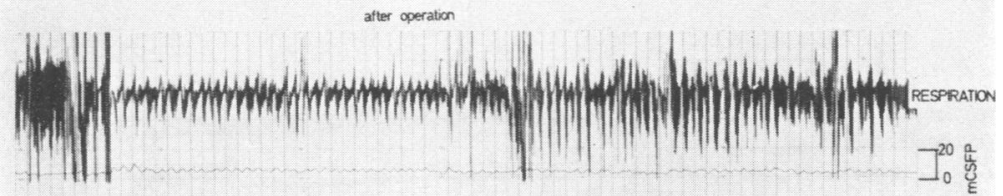
Patient was discharged four days later without neurological deficit.

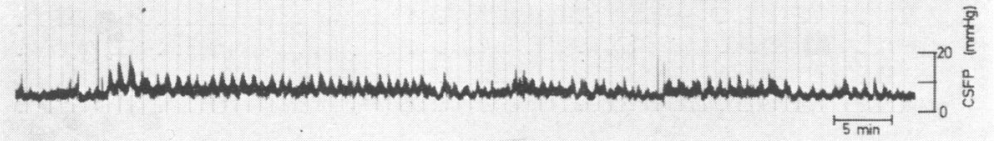

(a)

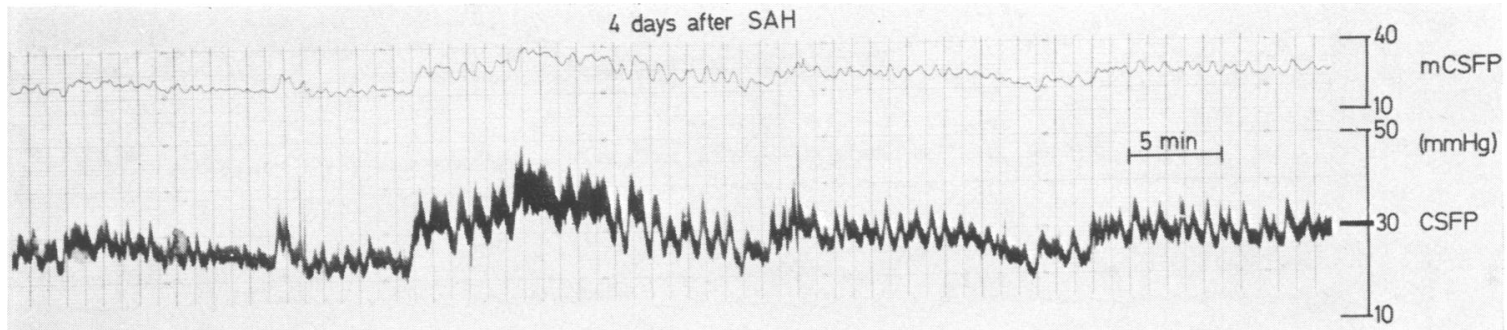

18 days after $\mathrm{SAH}$

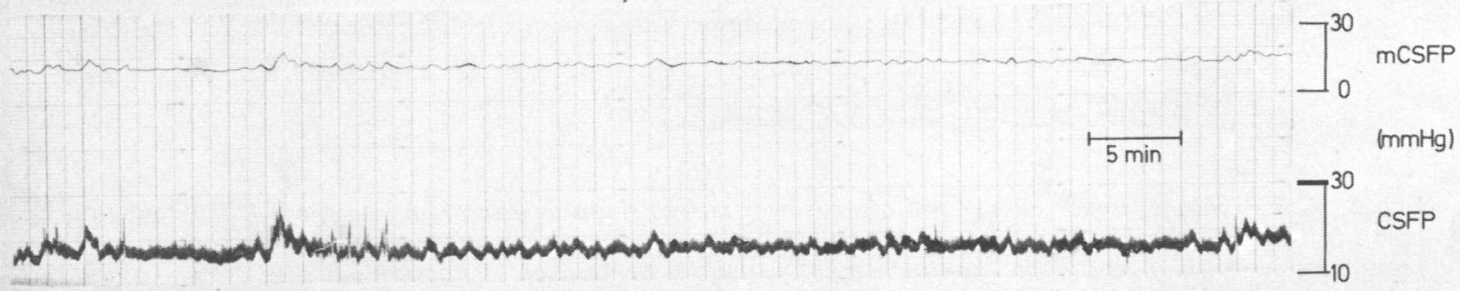


In the control group we never observed pressure elevations which exceeded the baseline pressure by more than $4 \mathrm{mmHg}$. The CSF pressure and

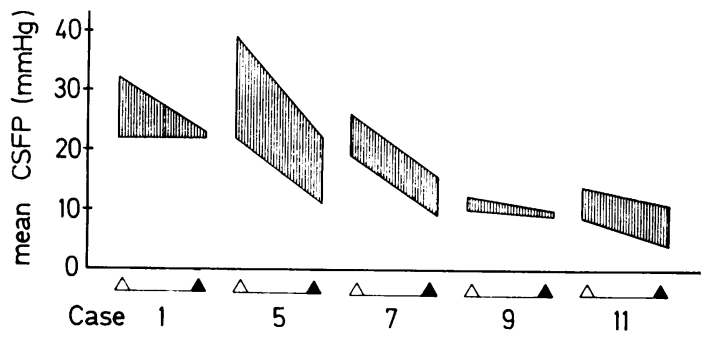

Fig. 4 Effect of shunt operation on CSF pressure. The highest and lowest CSF pressure are indicated before $(\triangle)$ and after $(\Delta)$ operation. Plateau waves are excluded. pressure pulsations were within normal limits in all controls.

Lundberg's C-waves were seen in both groups but were higher in the group with communicating hydrocephalus.

The reaction of CSF pressure to intrathecal infusion was classified as follows (Fig. 6):

Type $A$ : steep increase of CSF pressure immediately after start of infusion. Early complaints of headache and nausea which led to discontinuance of infusion.

Type B: slow but continuous rise of the CSF pressure during infusion with delayed complaints of headache and nausea.

Type C: only slight increase of the CSF pressure during infusion for a maximum of $60 \mathrm{~min}$. No complaints.

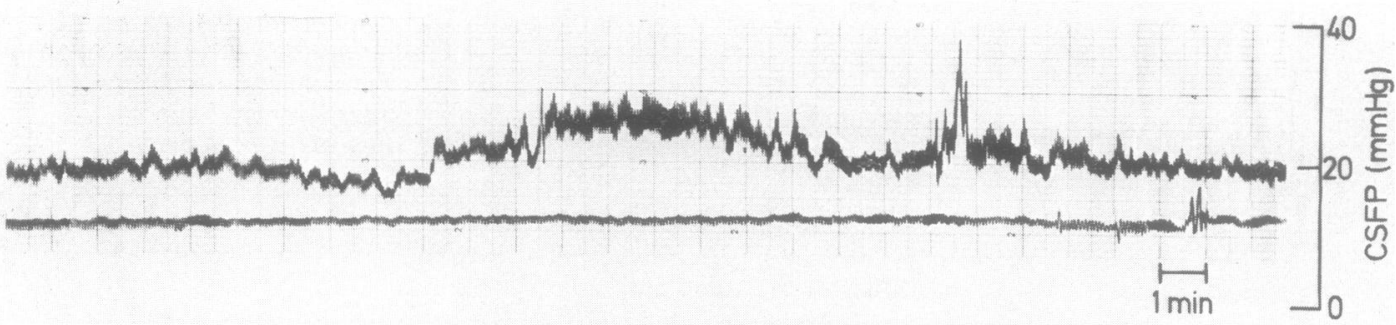

(a)
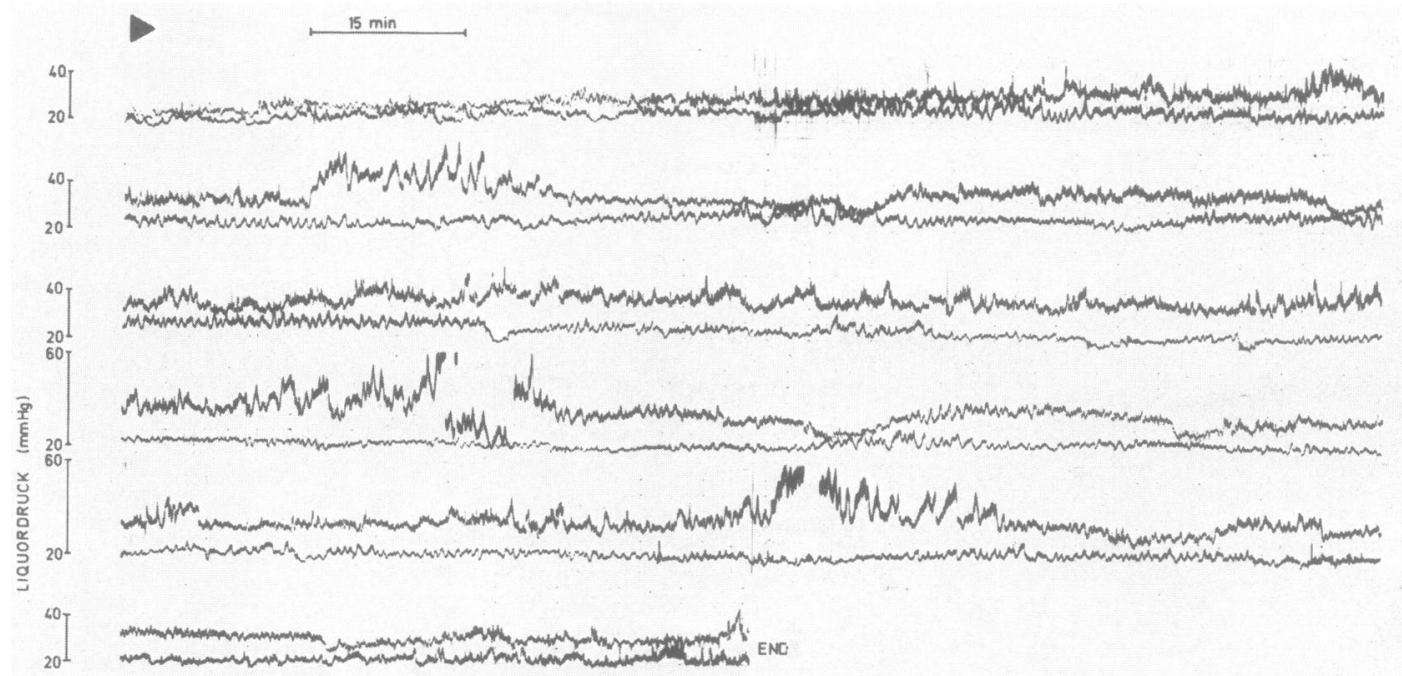

(b)

Fig. 5 CSFP before (upper curve) and after (lower curve) shunt surgery. Curve a reads from right to left, curve $b$ from left to right. Calibration is identical for pre-and postoperative recordings. (a) patient 7 . This section shows 27 min of a night monitoring; (b) patient 5. Section of 11 hours from the 24-hour study. CSF pressure ranges from 22 to $76 \mathrm{mmHg}$. Note in the fourth row a change of calibration due to high pressure. After surgery CSF pressure was measured between 16 and $22 \mathrm{~mm} \mathrm{Hg}$. 

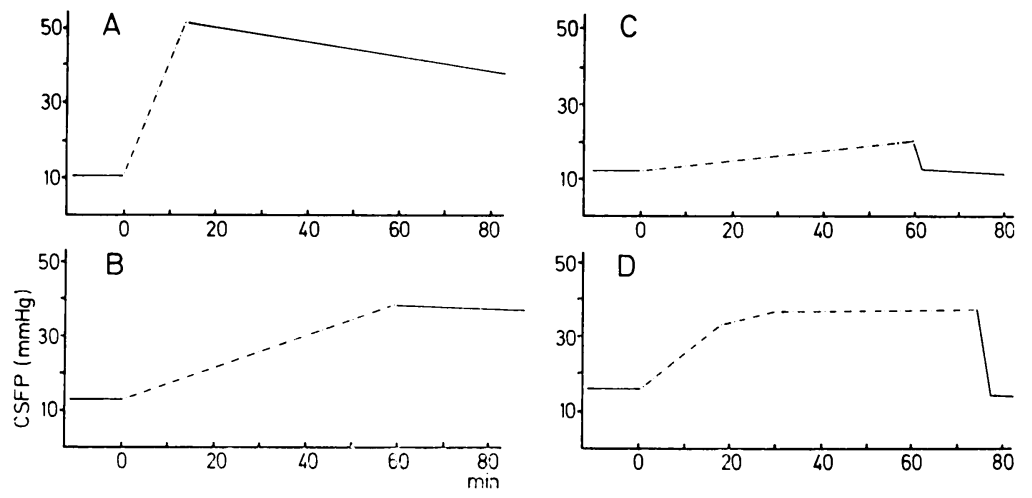

Fig. 6 Schematic drawing of the four types of CSF pressure response to intrathecal infusion. Explanation is given in results section of text. -.-.- = infusion.

Type D: initial increase until the CSF pressure reached a plateau which lasted for the rest of the infusion. No complaints.

In the $\mathrm{CH}$-group seven patients showed a normal reaction to the infusion (type $C$ and $D$ ). All seven patients with an abnormal response (type A or B) occasionally showed plateau waves in the continuous monitoring, but not all patients with plateau waves showed a pathological reaction to the infusion study. The three cases with type A reaction complained of headache and nausea after 11-17 min at a pressure between 28 and $46 \mathrm{mmHg}$. The three patients with type $B$ reaction reached their peaks within $20-39 \mathrm{~min}$ at a CSF pressure between 42 and $52 \mathrm{mmHg}$. The higher infusion rate was tested in six patients of this group. Only one patient did not complain. All others showed a type A or B reaction.

All patients of the control group could be listed in the infusion test as having type $\mathrm{C}$ or $\mathrm{D}$ response using the slower rate of infusion. In none of them did the CSF pressure exceed $37 \mathrm{mmHg}$. However, with the higher infusion rate in eight subjects, we noted in six a change to type $\mathrm{A}$ or $\mathrm{B}$ reaction with a maximum CSF pressure between 24 and $47 \mathrm{mmHg}$.

\section{Discussion}

After the work of Adams et al. (1965), it was accepted that in the chronic state of hydrocephalus with free communication between the ventricles and the spinal subarachnoid space the intrathecal pressure is normal ('normal pressure hydrocephalus'). Using an epidural transducer, however, Symon et al. (1972) demonstrated that paroxysmal elevations of intracranial pressure occurred in communicating hydrocephalus. They assumed that the dissociation between production and absorption of the CSF leads to the develop- ment of hydrocephalus internus, and that a later equalisation occurs with paroxysmal disturbance resulting in plateau waves. It has been stated that patients with plateau waves benefit more from a shunt operation than those without (Chawla et al., 1974).

Our data indicate that in some patients with communicating hydrocephalus the CSF pressure remains elevated, and that in other patients with average normal pressure the CSF pressure sometimes exceeds the normal range (Fig. 7). With non-continuous measurements of the CSF pressure these plateau waves may escape detection. Reduction of the pressure by a shunt drainage was associated with clinical improvement of varying degrees. The CSF pressure was normal in patients with cerebral atrophy from other causes. Plateau waves did not occur. From this point of view it would not be necessary in these patients to install a shunt.

The increased CSF pressure in some cases with chronic communicating hydrocephalus indicates that, at least in the acute phase, intracranial pressure is elevated and might damage brain tissue. This is validated by repeated measurements in case 4 and 14 (Fig. 3a), and other subjects (Fig. $3 b$ ). Since an elevated intracranial pressure may impair brain tissue functions by reduction of blood flow (Greitz et al., 1969; Mathew et al., 1974), CSF drainage should be considered as early as possible. If, however, CSF pressure decreases rapidly in the acute phase (Fig. $3 \mathrm{~b}$ ), a shunt should be considered only in the presence of a pathological intrathecal infusion test or plateau waves.

The infusion study originates from the work of Foldes and Arrowood (1948), and was further developed by Hussey et al. (1970). Wolinsky et al. (1973) and Trotter et al. (1974) argued that the lumbar infusion test contains methodological errors due to the movable needle. We used a 


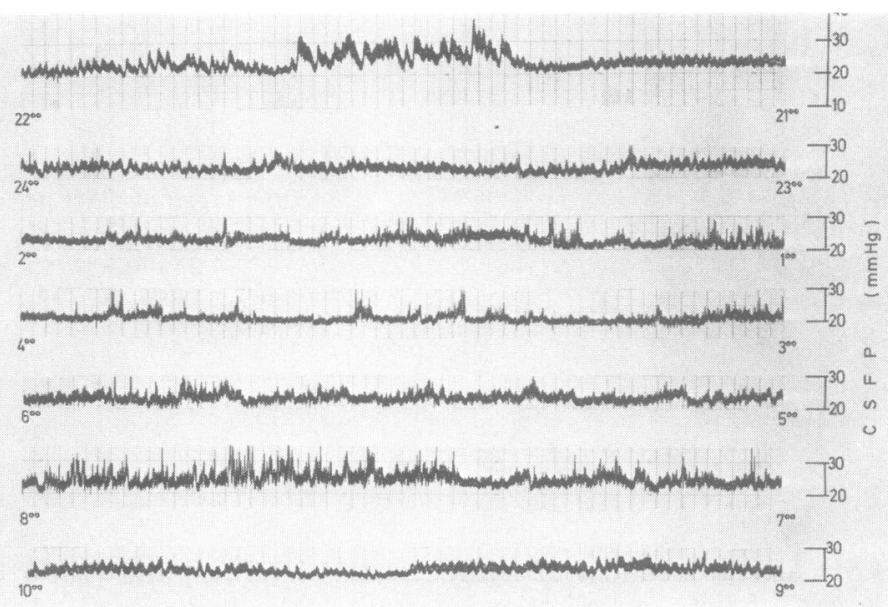

Fig. 7 CSF pressure before shunt surgery in patient 1 . Chart reads from right to left.

catheter which was in place before the infusion study for at least 24 hours. It was unlikely that it would slip from the subarachnoid space to the subdural space during the infusion.

The rate of CSF production in humans has been estimated as being between 0.26 and $0.65 \mathrm{ml} / \mathrm{min}$. The usual absorption rate may be exceeded by three to four times in normal subjects, and in some instances even by six to eight times (Hussey et al., 1970). These authors observed that in children and adults suffering from various diseases of the central nervous system, including communicating hydrocephalus, a reduced tolerance occurred to infusions at several rates. Since only one out of 14 patients with Alzheimer's disease showed a pathological reaction, the authors believed that a normal and disturbed absorption can be differentiated with this test.

In our study all patients of the control group tolerated well the infusion at a rate of $0.74 \mathrm{ml} / \mathrm{min}$. Seven subjects showed a mild continuous rise of the CSF pressure (type $C$ reaction) which at no time produced side effects. In these cases the total fluid (CSF produced and infused normal saline) probably exceeded the amount absorbed. However, it was not enough to produce clinical symptoms within $60 \mathrm{~min}$. These results were classified as being normal. The other six subjects showed an initial increase of the CSF pressure with achievement of a plateau (type $\mathrm{D}$ reaction). Again, no side effects were noted. The plateau of pressure indicates a level at which the amount of absorbed fluid equals the total amount produced.

At this rate seven patients with communicating hydrocephalus showed a pathological reaction (type A or B reaction, Fig. 8) and seven patients showed a type $\mathrm{C}$ or $\mathrm{D}$ reaction. If the time to achieve the maximum CSF pressure during infusion and the initial and maximum CSF pressure are compared, it may be seen that a distinct differentiation between control patients and patients with communicating hydrocephalus cannot be made (Fig. 9). Using the doubled infusion rate, the increase of the CSF pressure was faster in five out of six patients with communicating hydrocephalus than in all eight control patients (Fig. 9).

It appears unfounded to shunt patients who have normal intracranial pressure, no plateauf waves, and normal reaction to the infusion study even in the presence of other symptoms of communicating hydrocephalus. In these patients reduction of the CSF pressure will not improve tissue functions. Some authors have demonstrated clinical improvement in individuals with Alzheimer's disease after shunting due to increased cerebral blood flow (Appenzeller and Salmon, 1967; Salmon and Armitage, 1968). In collaborative work, Mathew and coworkers (1975) found no clinical improvement or increase of cerebral blood flow by draining CSF in patients with presenile dementia. In contrast to communicating hydrocephalus, reduction of cerebral blood flow in Alzheimer's disease is not due to constant or temporarily increased intracranial pressure, but to neuronal atrophy of unknown cause. Cases of presenile dementia have to be clarified by medical history, clinical examination, and diagnostic procedures to eliminate the possibility of obstruction in the subarachnoid space or reduced CSF absorption.

One of the cases in the communicating hydrocephalus group, who improved after shunting, 


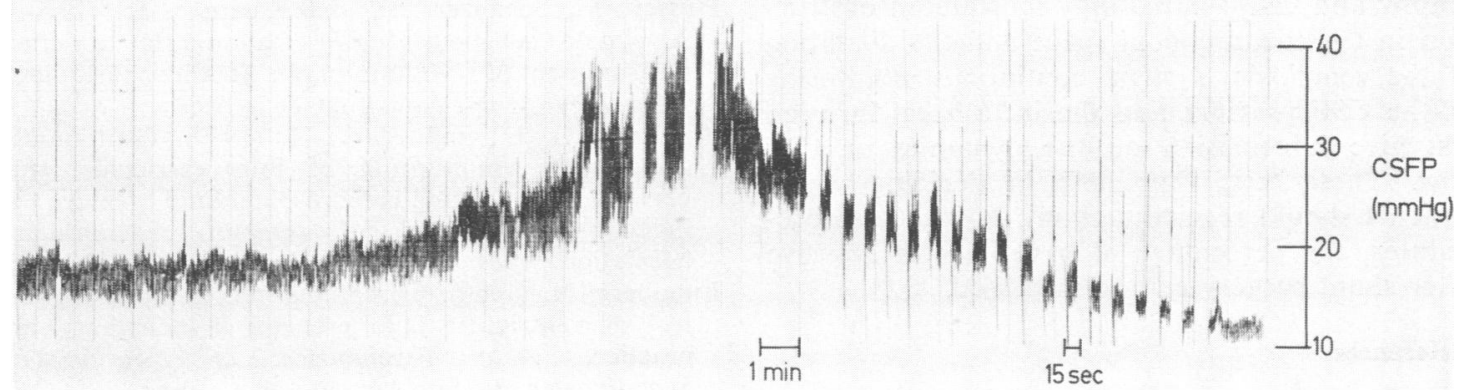

(a)

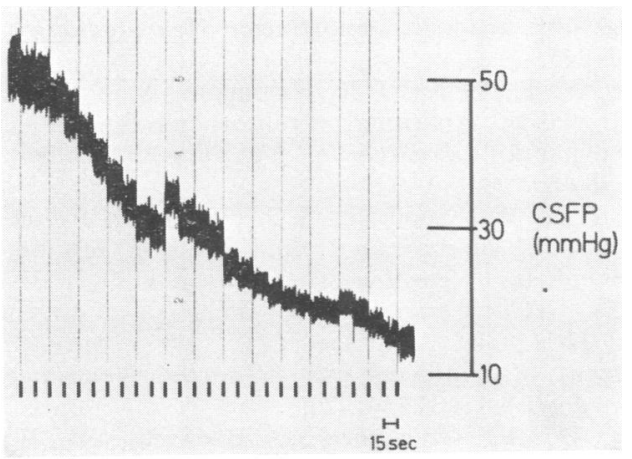

(b)

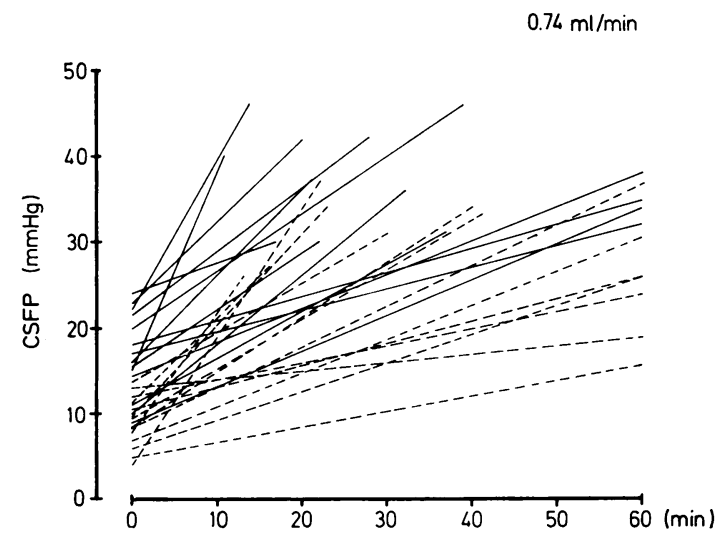

(a)
Fig. 8 Intrathecal infusion test. Pictures read from right to left. (a) patient 7. Increase of CSF pressure from 12 to $25 \mathrm{mmHg}$ within $17 \mathrm{~min}$. The infusion was stopped at the beginning of the ' 1 min' mark. CSF pressure increased further for 3 min. (b) patient 5. There is no gap between intervals of recording since the chart was stopped for infusion. CSF pressure was recorded each time for $15 \mathrm{~s}$. CSF pressure reached $52 \mathrm{mmHg}$ after 28 min of infusion. Complaints vanished with reduction of CSF pressure after end of infusion.

Fig. 9 Increase of CSF pressure during intrathecal infusion. Steady state CSF pressure (at zero point), time to achieve maximum CSF pressure, and maximum CSF pressure are compared. (a) infusion rate $0.74 \mathrm{ml} / \mathrm{min}$. It is not possible to differentiate accurately between all patients with communicating hydrocephalus and controls; (b) infusion rate $1.47 \mathrm{ml} / \mathrm{min}$. Steep increase of CSF pressure in most of the patients with communicating hydrocephalus..$--=$ control group.- $-=C H$-group.

showed a normal reaction to both infusion rates but showed plateau waves. We, therefore, agree with Wolinsky et al. (1973) that the indication for surgical therapy should not be made on the basis of one test only. Both tests together are probably capable of differentiating between both groups if more than one infusion rate is employed (Nelson and Goodman, 1971). Whereas pneumoencephalo- 
graphy and CSF scintigraphy indicate an obstruction in the subarachnoid space and the dilatation of the ventricular system, continuous monitoring of the CSF pressure and the intrathecal infusion test give information on the dynamics of CSF flow. These tests thus help in deciding which patients should receive a shunt. Using these procedures, the percentage of patients who improve after shunt surgery can be increased.

\section{References}

Adams, R. D., Fisher, C. M., Hakim, S., Ojemann, R. G., and Sweet, W. H. (1965). Symptomatic occult hydrocephalus with 'normal' cerebrospinal fluid pressure. New England Journal of Medicine, 273, 117-126.

Appenzeller, O., and Salmon, J. H. (1967). Treatment of parenchymatous degeneration of the brain by ventriculo-atrial shunting of the cerebrospinal fluid. Journal of Neurosurgery, 26, 478-482.

Chawla, J. C., Hulme, A., and Cooper, R. (1974). Intracranial pressure in patients with dementia and communicating hydrocephalus. Journal of Neurosurgery, 40, 376-380.

Foldes, E. F., and Arrowood, J. G. (1948). Changes in cerebrospinal fluid pressure under the influence of continuous subarachnoid infusion of normal saline. Journal of Clinical Investigation, 27, 346351.

Garretson, H. D., and Brindle, G. F. (1972). Effects of ventriculoatrial shunting on CSF dynamics. In Cisternography and Hydrocephalus, pp. 323-334. Edited by H. C. Harbert. Charles C. Thomas: Springfield, Illinois.

Greitz, T. V. B., Grepe, A. O. L., Kalmér, M. S. F., and Lopez, J. (1969). Pre- and postoperative evaluation of cerebral blood flow in low-pressure hydrocephalus. Journal of Neurosurgery, 31, 644-651.

Hartmann, A., and Alberti, E. (1977). Eine einfache Methode zur kontinuierlichen Messung des Liquordrucks (A simple method for continuous monitoring of cerebrospinal fluid pressure). Acta Neurochirurgica, 36, 201-214.
Hussey, F., Schanzer, B., and Katzman, R. (1970). A simple constant-infusion manometric test for measurement of CSF absorption: II. Clinical studies. Neurology (Minneapolis), 20, 665-680.

Kaufman, G. E., and Clark, K. (1970). Continuous simultaneous monitoring of intraventricular and cervical subarachnoid cerebrospinal fluid pressure to indicate development of cerebral or tonsillar herniation. Journal of Neurosurgery, 33, 145-150.

Lundberg, N. (1960). Continuous recording and control of ventricular fluid pressure in neurosurgical practice. Acta Psychiatrica et Neurologica Scandinavica, 36, Supplement 149.

Mathew, N. T., Meyer, J. S., and Hartmann, A. (1974). Diagnosis and treatment of factors complicating subarachnoid hemorrhage. Neuroradiology, 6, 237-245.

Mathew, N. T., Meyer, J. S., Hartmann, A., and Ott, E. O. (1975). Abnormal cerebrospinal fluid-blood flow dynamics. Archives of Neurology (Chicago), 32, 657-663.

Nelson, J. R., and Goodman, S. J. (1971). An evaluation of the cerebrospinal fluid infusion test for hydrocephalus. Neurology (Minneapolis), 21, 10371053.

Salmon, J. H., and Armitage, J. L. (1968). Surgical treatment of hydrocephalus ex vacuo. Neurology (Minneapolis), 18, 1223-1226.

Shenkin, H. A., Greenberg, J., Bouzarth, W. F., Gutterman, P., and Morales, J. O. (1973). Ventri- 2 cular shunting for relief of senile symptoms. Journal of the American Medical Association, 225, 14861489.

Symon, L. (1972). Intracranial pressure monitoring in communicating hydrocephalus. Proceedings of the Royal Society of Medicine, 65, 888-890.

Symon, L., Dorsch, N. W. C., and Stephens, R. J. (1972). Pressure waves in so-called low-pressure hydrocephalus. Lancet, 2, 1291-1292.

Trotter, J. L., Luzecky, M., Siegel, B. A., and Gado, M. (1974). Cerebrospinal fluid infusion test. Neurology (Minneapolis), 24, 181-186.

Wolinsky, J. S., Barnes, B. D., and Margolis, M. T. (1973). Diagnostic tests in normal pressure hydrocephalus. Neurology (Minneapolis), 23, 706-713. 